\title{
Autonomia do Banco Central: A Legitimidade da Política Macroeconômica no Primeiro Mandato de Lula Frente aos Banqueiros
}

\author{
RODOLFO DiAs ${ }^{1}$
}

\begin{abstract}
Resumo
O artigo analisa a política de autonomia do Banco Central praticada no primeiro mandato do governo Lula. A análise justifica-se pela importância da instituição na formulação de políticas econômicas no governo, e pela necessidade de legitimação da instituição pelos empresários financeiros, em especial pelos bancos. Pretendese observar o posicionamento dos banqueiros nesse "jogo de barganha" que se estabelece no sistema bancário brasileiro. As fontes serão as manifestações de banqueiros na grande imprensa escrita, especificamente nos jornais "Folha de São Paulo" e "Valor Econômico". Dois temas serão discutidos no artigo: Henrique Meirelles como presidente do Banco Central; e a reformulação do artigo 192 da Constituição de 1988. Percebe-se que a pauta reivindicativa dos banqueiros não foi integralmente cumprida (institucionalização da autonomia), mas isso não implicou em uma crítica à política governamental.
\end{abstract}

Palavras-Chave: Autonomia do Banco Central. Governo Lula. Banqueiros.

\section{Central Bank's autonomy: Legitimacy of MACro-economic POLICY IN LULA'S FIRST MANDATE BEFORE BANKERS}

\footnotetext{
Abstract

The article analyzes the Central Bank's autonomy policy pursued in Lula's first mandate. The analysis is justified by the institution's importance in the formulation of economic policies, and the need of institutional

1 Doutorando em Sociologia Política pela Universidade Federal de Santa Catarina (UFSC), Brasil.rodolfo.dias@gmail.com. 
legitimacy by financial entrepreneurs, especially by banks. It is intended to observe the position of the bankers in that "bargaining game" that is established in the brazilian banking system. The research sources are the manifestations of bankers in press, specifically in the newspaper "Folha de São Paulo" and "Valor Econômico". Two topics will be discussed in the article: Henrique Meirelles as president of the Central Bank; and the amendment of Article 192 of the 1988 Constitution. Is perceived that the demanding agenda of the bankers has not fully complied with (institutionalization of autonomy), but this did not imply a criticism ofgovernment policy.

Keywords: Central Bank's autonomy; Lula's government; bankers.

\section{O Debate Sobre “Autonomia do Banco Central” e a Importância da OPINIÃo dos BANQUEIROS}

O tema "autonomia do Banco Central" é objeto de intensos debates jornalísticos e acadêmicos. Banqueiros e economistas possuem participação direta nesses debates. Neles, prevalece a defesa dessa autonomia, realizada por argumentos embasados na perspectiva neoliberal. Esse tipo de argumento foi sintetizado por Mendonça (2000, p. 101): "A discussão que envolve a independência dos bancos centrais tem apresentado como principal argumento teórico a hipótese de que policy-makers são sujeitos ao viés inflacionário intrínseco à condução da política monetária."

Diante dessa característica intrínseca, seria importante separar os agentes responsáveis pela estabilidade monetária (o Banco Central) do resto dos agentes estatais. Esse argumento pode ser encontrado em Alan Blinder, acadêmico reconhecido na área e que também foi vicechairman do Federal Reserve Board (FED).

[...] políticos em países democráticos - e até mesmo não democráticos - não são conhecidos nem por sua paciência nem por sua visão aguda de longo prazo. Nem o são os meios de comunicação de massa, nem a população. E nenhum desses grupos entende muito bem as longas defasagens na política monetária (BLINDER, 1999, p 73). 
O argumento de Blinder é característico dos técnicos presentes nos Bancos Centrais. O problema desse argumento não é a inexistência de correlação entre tais variáveis - verificada por Blinder nos casos dos Bancos Centrais no período pós guerra que possuíam o objetivo específico de conter a inflação, feita a ressalva de que se o objetivo fosse combater a deflação talvez essa não seria a instituição mais adequada. E nem a incompatibilidade do argumento com o sistema democrático - também, no argumento de Blinder, a autonomia deve ser pensada em termos instrumentais, e não de objetivos, os quais deveriam ser definidos pelos sistemas políticos democráticos.

Essa defesa da autonomia do Banco Central é problemática por ser normativa. Ela parte de dois pressupostos contestáveis: que os agentes governamentais possuem viés inflacionário; e que o Banco Central possui a característica intrínseca de busca da estabilidade monetária. Nas palavras de Sola, Garman e Marques (1998, p. 115, tradução nossa): "A noção que prevalece acerca da autoridade monetária é basicamente normativa. Ela estipula a independência dos bancos centrais em relação à arena política como pré-condição para o alcance de uma estabilidade de preços durável."

O problema é explicar a correlação entre independência do Banco Central e contenção do processo inflacionário pela natureza dos atores envolvidos, que proveria capacidade instrumental de realizar o objetivo de combate à inflação.

Buscando uma perspectiva analítica alternativa, Sola, Garman e Marques (1998) propõem uma discussão acerca da autonomia do Banco Central baseada em argumentos sobre legitimidade ao invés de eficiência. Fazendo uma comparação com o poder judiciário, os autores desenvolvem o argumento de que a autoridade monetária necessita construir politicamente sua legitimidade nas conjunturas políticas locais. Sob essa lógica, explicam o processo de centralização do controle monetário nas mãos do Banco Central através do processo 
de legitimação que essas autoridades monetárias adquiriram com a estabilização da inflação. Esse argumento é o inverso do que a perspectiva justificadora da autonomia prega. Enquanto essa estabelece que para o alcance da estabilidade monetária é necessário um Banco Central autônomo, Sola, Garman e Marques (1998) afirmam o contrário: é justamente a estabilidade monetária que permitiu o Banco Central adquirir níveis de autonomia maiores. Essa inversão argumentativa é justificada pela análise histórica do desenvolvimento dos Bancos Centrais, os quais adquiriram autonomia somente depois da estabilização da moeda.

Ao colocar o problema nesses termos, os autores contribuíram por retirar o debate sobre autonomia do Banco Central da esfera normativa. E o fazem com objetivos definidos. O grande problema teórico de Sola, Garman e Marques (1998) é debater a autonomia como não-contraditório ao sistema político democrático. Para eles, o processo de autonomização da autoridade monetária não teria o sentido de restringir o acesso ao processo decisório da política monetária, mas sim de construção social da legitimidade da autoridade monetária. Nas situações históricas em que a estabilidade monetária torna-se um problema político de primeira ordem (os processos econômicos de "hiperinflação") cria-se uma situação em que a autoridade monetária pode adquirir legitimidade frente à população. E a aplicação de uma política que seja bem sucedida no combate à inflação concede legitimidade social para essa autoridade monetária (SOLA; GARMAN; MARQUES, 1998, p. 129). A estabilidade monetária torna-se assim um objetivo social comum, e o sucesso do Banco Central na criação e manutenção dessa estabilidade confere a esse ator social legitimidade, não sendo portanto um processo político anti-democrático.

O objetivo dessa pesquisa, ao discutir autonomia, não é encontrar alguma possível conciliação entre democracia e autonomia do Banco Central. O problema da legitimidade não está sendo pensado 
como um reconhecimento difuso, posto para toda a população indiferenciadamente. Compreender o papel econômico do Banco Central requer a reflexão sobre um dos elementos mais centrais para o funcionamento de qualquer sistema bancário: o sistema de regras de propriedade (legal, regulamentar e institucional) que depende do poder policial do Estado (CALOMIRIS; HABER, 2014, p. 27-28). Mas a atividade dos atores e das instituições envolvidas no funcionamento do sistema bancário, longe de estar direcionadas "funcionalmente" para a estabilidade do sistema, acabam se direcionando de acordo com seus próprios interesses, que por vezes pode ser oposto à essa estabilidade. Os atores interagem seguindo sua própria lógica de interesses, designada por Calomiris e Harber de "jogo de barganha bancário" (game of bank bargains). Os autores definem tal conceito da seguinte maneira:

Nós chamamos esse processo de negociação de Jogo de Barganha bancário. Os jogadores são aqueles com uma participação na performance do sistema bancário: o grupo no controle do governo, banqueiros, acionistas minoritários, devedores e depositários. As regras, que são definidas pelas instituições políticas da sociedade determinam quais outros grupos devem ser incluídos na parceria governo-banqueiro e quais podem ser deixadas de fora no frio porque as regras do sistema político deixam eles sem poder (CALOMIRIS; HABER, 2014, p. 13, tradução nossa).

Estudar a autonomia do Banco Central (ou a construção desta) sob essa perspectiva coloca o problema da relação entre o Estado e os bancos, problematizando as posições e os interesses de tais atores no processo político de definição dessa autonomia. Nesse sentido, a pesquisa irá identificar a legitimidade que a forma de autonomia construída no Brasil antes do governo Lula possuía entre os banqueiros; quais eram os problemas dessa forma de autonomia 
segundo esses empresários; e seu posicionamento diante da tentativa de se regulamentar o sistema institucional do Banco Central.

Para identificar os termos nos quais esse "jogo de barganha” é jogado, devemos levar em consideração o sistema de ideias econômicas que prevalece em determinado período, e como esse sistema é utilizado politicamente pelas partes. A perspectiva econômica dominante, construída pelo mainstream, possui um forte viés "pró-mercado" que é fundamento do que se denomina "políticas neoliberais". Como mostra o trabalho de Cavalieri, Perissinotto e Dantas (2015), essa formação acadêmica mainstream e também os vínculos profissionais com instituições privadas são características marcantes dos diretores do Banco Central do Brasil, em especial daqueles que ocupam diretorias responsáveis pela formulação das políticas econômicas do governo. Assim, é possível perceber pela própria composição da direção da instituição uma captura cognitiva e um alinhamento de interesses observado na trajetória profissional de seus membros. Considerando tais fatores e incluindo a força econômica das instituições bancárias e financeiras no Brasil, a afirmação de Loureiro, Santos e Gomide (2011) consegue sintetizar os termos do "jogo de barganha bancário" que ocorre no Brasil:

No caso do Banco Central, sua impermeabilidade às pressões que the tem permitido praticar política de juros elevados há mais de uma década não se explica por uma ideia abstrata "de racionalidade econômica", por uma lógica estritamente técnica e neutra, como muitos afirmam. Trata-se de política imposta pelo chamado "poder de fogo" do mercado financeiro, que pode constranger os governos que se financiam através do endividamento público interno ou externo, impondolhes a "autonomia" (se não legal, pelo menos, de fato) da autoridade monetária, "protegendo-a" contra pressões do restante do sistema político e, portanto, gerando credible commitment (LOUREIRO; SANTOS; GOMIDE, 2011, p. 72, grifo nosso). 
Pensar a relação bancos e governo no sistema bancário em termos de "jogos de barganha" implica em distinguir interesses. O que é possível observar na realidade brasileira - possivelmente aplicável em outros contextos - é que uma das vantagens estratégicas dos bancos nesse jogo de barganha é a proximidade das ideias daqueles responsáveis por regular o sistema financeiro e os interesses das entidades privadas. Esses responsáveis, mais do que simplesmente "obedecer" às ordens do "mercado financeiro", são mais suscetíveis aos mecanismos de pressão das instituições financeiras por estarem orientados por essa mesma visão de mundo.

Dar autonomia a esses administradores é uma peça chave para impedir que o resto do aparato estatal possa redirecionar o comportamento para um sentido distinto dos interesses dos bancos. É sob essa perspectiva que a "legitimidade" do Banco Central do Brasil em relação aos banqueiros será tratada.

\section{O Tipo de Autonomia do Banco Central do Brasil e Sua Construção Histórica}

Quem realizou o plano de estabilização monetária brasileira, o plano Real, foi Fernando Henrique Cardoso e sua equipe econômica. Embora seja possível observar o debate sobre autonomia do Banco Central em diferentes períodos da história (NOVELLI, 1998), foi no governo de Fernando Henrique Cardoso que essa instituição sofreu diversas alterações relevantes.

Segundo Novelli (1998), a autonomia do Banco Central no Brasil durante o governo Fernando Henrique Cardoso não foi construída juridicamente. Ela limitou-se à liberação operacional do Banco Central, uma não intervenção realizada por opção política. Além disso, delimitou a ação do Banco Central ao que o autor chamou de "funções clássicas", em especial a manutenção da estabilidade 
do poder de compra da moeda nacional (NOVELLI, 1998, p. 15). Nesse sentido, o Banco Central passou a possuir grande margem de autonomia para definir a política de juros do governo por meio do controle da Taxa Selic, mesmo não podendo se opor diretamente à política econômica mais geral.

A autonomia que existia antes da entrada do governo Lula ocorria mais pelo projeto político adotado pelo governo do que pela limitação institucional de intervenção dentro do órgão. Mas com a eleição de Lula pelo Partido dos Trabalhadores, que era oposição ao governo anterior de Fernando Henrique Cardoso, se colocava o problema da possibilidade de mudança nas relações dentro do "jogo de barganha bancário". Diante dessa mudança, a estratégia dos bancos em orientar o comportamento governamental estava em risco? Os riscos ao posicionamento dos bancos se colocavam em duas frentes. Primeiro, existia o problema de qual equipe econômica assumiria o Banco Central. Por mais que essa equipe agisse de forma autônoma, essa equipe não necessariamente aplicaria as mesmas políticas econômicas que estavam sendo aplicadas no governo Fernando Henrique Cardoso. Segundo, mesmo que iniciasse com uma política de continuidade, havendo a abertura institucional, em outro momento o governo poderia mudar essa equipe ou impor externamente a alteração da política econômica.

Existiria a necessidade de, além de possuir uma equipe disposta a aplicar a política econômica defendida pelo mainstream, de isolá-los adequadamente. Para tratar desses dois problemas, será considerada a posição dos banqueiros em relação à dois fatos específicos: a escolha de Henrique Meirelles para a presidência do Banco Central; e a alteração do artigo 192 da Constituição de 1988, que trata do sistema financeiro nacional. 


\section{A Política Econômica Adotada pelo Banco Central: a Opiniño dos}

\section{Banqueiros Diante da Indicação de Henrique Meirelles}

A entrada de Henrique Meirelles na presidência do Banco Central é relevante, pois indicava o tipo de política econômica que seria adotada durante o governo. Além de ter sido presidente do BankBoston no Brasil e também ter sido membro da diretoria executiva da FEBRABAN durante a década de 90, Henrique Meirelles foi eleito em 2002 deputado estadual pelo $\mathrm{PSDB}^{2}$, principal partido concorrente do PT. Esse fato poderia ter gerado a interpretação de que a gestão do Banco Central seria feita de maneira mais distante dos posicionamentos partidários do PT. A pesquisa irá verificar se essa interpretação foi feita efetivamente pelos banqueiros e quais foram os principais argumentos usados nesse posicionamento.

Depois do processo eleitoral de 2002 houve boatos na grande imprensa que levantavam a possibilidade de manutenção de Armínio Fraga, então presidente do Banco Central, no cargo. Tais boatos foram desmentidos por José Dirceu e Lula nos dias 20 de novembro e 05 de dezembro desde mesmo ano, respectivamente (DIRCEU..., 2002; RIPARDO, 2002). Segundo relato de Armínio Fraga à "Folha de São Paulo", houve conversas entre ele e Antônio Palocci a respeito da manutenção da diretoria do Banco Central em seus respectivos cargos (FREIRE, 2002), mas mesmo antes das eleições Palocci já havia apontado a dificuldade política em manter a mesma figura sobre o comando do Banco Central, mesmo que em uma etapa transitória (PINTO, 2002).

A questão política desse momento é a dualidade na posição do Partido dos Trabalhadores. O partido afirmava a manutenção das políticas econômicas até então implementadas, mas também defendia a necessidade de se alterar a pessoa que ocupava o cargo principal da

2 Embora tenha saído do PSDB e entrado para o PMDB para assumir o cargo de presidente do Banco Central. 
instituição. Argumenta-se que era necessária a entrada de um novo presidente do Banco Central que fosse capaz de manter a legitimidade da autoridade monetária. E o nome escolhido para essa função foi o de Henrique Meirelles.

Entre os agentes do sistema financeiro, é difícil afirmar que o nome de Meirelles foi um consenso. É possível identificar na mídia impressa a presença de opiniões contarias à nomeação de Henrique Meirelles e de Antônio Hermann (diretor de Política Monetária do governo). Essas opiniões vinham principalmente de bancos internacionais, como o Deutsche Bank e o Credit Suisse First Boston (PERFIL..., 2002), e de analistas de corretoras e de bancos de investimentos, como Liabilities Securities, Morgan Stanley e Lehman Brothers (FRAGA; AITH, 2002). A principal crítica contida nessas opiniões era o perfil político que tanto Meirelles como Hermann possuíam. Assim se expressou Paulo Vieira da Cunha, analista da Lehman Brothers, a respeito de Henrique Meirelles: “É uma indicação muito boa. Não tenho dúvidas da capacidade de Meirelles. Mas temos que reconhecer que ele optou pela profissão de político. O ideal, mas não essencial, talvez fosse a escolha de um técnico." (FRAGA; AITH, 2002).

Mas tal opinião não foi encontrada entre os banqueiros brasileiros. O posicionamento de Gabriel Jorge Ferreira, então vicepresidente do Unibanco e presidente da FEBRABAN, é representativo nesse sentido: "Não vejo nenhum problema. Aliás, tenho minhas dúvidas de que ele não tenha esse perfil operacional, depois de dirigir por tanto tempo o BankBoston. Ainda que exista uma lacuna, ela poderá ser preenchida pela equipe que ele vai constituir." (FRAGA; AITH, 2002).

Além desse pronunciamento, Ferreira declarou que não via contradição no fato de Meirelles ter sido eleito pelo PSDB e de ter assumido o Banco Central (RIBEIRO, 2002). Também afirmou que 
sua nomeação correspondia às "expectativas do mercado", com seu perfil "liberal e com certo grau de conservadorismo" (MEIRELLES..., 2002b). Inclusive, Ferreira chega a defender não só Henrique Meirelles como também Antônio Hermann, destacando sua competência como “empresário financeiro" (PRESIDENTE..., 2002).

Não só o representante da principal entidade de banqueiros do Brasil apareceu manifestando seu apoio à escolha de Henrique Meirelles. O presidente executivo do Santander, Miguel Jorge, também fez declarações de apoio. Destacou que Alan Greenspan, então presidente do FED (Banco Central dos Estados Unidos), não possuía o perfil de operador do mercado financeiro e que o cargo de presidente do Banco Central não deveria ter essa exigência; afirmou ainda que Meirelles possuía os atributos para formar uma equipe coesa no Banco Central (MIGUEL..., 2002). Também é observável declarações de banqueiros pequenos (Banco Fibra) e de algumas entidades financeiras (BCP Securities e Lloyds TSB) manifestando seu apoio à entrada de Meirelles e rebatendo as críticas de excesso de perfil político do novo presidente do Banco Central (FRAGA; AITH, 2002; FLUXO..., 2002).

Assim, é perceptível o impacto que a saída de Armínio Fraga causou dentro do setor financeiro. Mas a opção de Lula por Henrique Meirelles foi capaz de manter opiniões favoráveis acerca da organização do Banco Central, e, portanto, manteve a legitimidade da autoridade monetária entre os banqueiros.

Mas além da opinião dos banqueiros em relação à escolha de Meirelles, também é importante analisar a opinião desses empresários em relação à política econômica que foi efetivamente adotada. Mesmo antes de tomar posse (em 27 de dezembro de 2002), Henrique Meirelles já havia declarado na imprensa que a equipe econômica da diretoria do Banco Central iria permanecer e que a política governamental se basearia na austeridade fiscal e equilíbrio monetário e cambial (MEIRELLES..., 2002a). No seu discurso de posse, Meirelles apresentou 
um posicionamento bastante sintonizado com as declarações feitas na "Carta ao povo brasileiro", mas sem nenhum tipo de crítica ao governo passado. Aliás, o que não faltou foram elogios ao presidente anterior do Banco Central, Armínio Fraga.

Meirelles destacou o profissionalismo do seu antecessor e elogiou o papel desempenhado por ele no processo de transição, bem como afirmou que o "modelo de atuação do Banco Central" adotado após 1999, legado da gestão de Armínio Fraga, teria sido muito importante para o país (MEIRELLES, 2003, p. 5-6). Por "modelo de atuação" Meirelles entedia a especialização das funções do Banco Central na estabilidade de preços.

É importante notar, no entanto, que o foco principal de avaliação de uma política de investimentos reside no modelo de atuação do Banco Central. Sendo responsável por áreas de Mercados de Capitais, Moedas, Mesas de Operação, Créditos Corporativos e Soberanos com atuação em vários países, tenho segurança em concluir que é consenso no mundo de hoje que Bancos Centrais a que foram impostas multiplicidade de funções e metas traçam uma história de insucessos. Bancos Centrais de sucesso são aqueles que têm como único mandato a estabilidade de preços (MEIRELLES, 2003, p. 5, grifo nosso).

Sendo a estabilidade monetária estabelecida como a principal meta do Banco Central, o novo presidente do Banco Central propõe o "regime de metas de inflação" como o mais adequado (MEIRELLES, 2003, p. 7), aliado ao "regime de câmbio flutuante" (MEIRELLES, 2003, p. 8). Basicamente, Henrique Meirelles reafirma, ao elogiar o seu antecessor e ao defender tais funções do Banco Central, a manutenção da política monetária até então implementada. Como Novelli (1998) colocou, tais "funções clássicas" do Banco Central foram implementadas durante o Governo Fernando Henrique Cardoso; e o discurso de posse de Meirelles apontou justamente para a manutenção de tal política econômica. 
O discurso conteve, além disso, uma convergência muito forte com o discurso de crescimento econômico apresentado na "Carta ao Povo Brasileiro", reforçando os compromissos internacionais do Brasil, a política de superávit primário e o objetivo de realização de "reformas estruturais". Ao final do discurso, Meirelles apresenta propostas políticas específicas mais ou menos contraditórias com os interesses dos banqueiros.

Essas ações e medidas devem ser complementadas com medidas microeconômicas, como as propostas para a redução do spread bancário, da nova lei de concordatas e falências, buscando baratear e disseminar o crédito, o que também inclui o projeto de micro-crédito, além do avanço do crédito via cooperativas, o aprofundamento do mercado de capitais, dos mecanismos de captação e do repasse de recursos Nacionais e Internacionais para estimular o investimento (MEIRELLES, 2003, p. 15).

Ao mesmo tempo em que propõe uma política de redução do spread bancário ${ }^{3}$, também prevê uma política de estímulo ao crédito e ao mercado de capitais, assim como uma política de falências mais favoráveis ao sistema financeiro. $\mathrm{O}$ ator estatal propôs assim a redução de uma das grandes fontes de ganho dos bancos seguindo, dentro do "jogo de barganhas bancário", a lógica que orienta o governo (tentar aumentar o volume de crédito disponível na economia). Mas o faz atendendo a uma série de reivindicações dos próprios banqueiros.

Nos comentários dos banqueiros em relação a esse discurso, percebe-se que não houve nenhum comentário em relação a essa proposta de "redução do spread bancário". Em geral os comentários foram elogiosos. Gabriel Jorge Ferreira, presidente da FEBRABAN, falou queo Banco Centraljá agia como autônomo, elogiou a manutenção da equipe econômica anterior, e considerou positivo o "compromisso com as metas de inflação" no discurso de Meirelles (RIBEIRO, 2002).

3 O spread bancário é a diferença entre os juros cobrados aos emprestadores e os juros pagos aos depositários 
Cristiano Buarque, então presidente da Confederação Nacional das Instituições Financeiras (CNF), também elogiou o discurso, destacando que o ponto central foi o destaque ao combate à inflação, e que se mostrava confiante na redução desta na metade de 2003 (COMBATE..., 2003). Pedro Moreira Salles, presidente do Unibanco, elogiou o compromisso do novo presidente do Banco Central com a estabilidade de preços e afirmou que isso havia contribuído bastante para o "otimismo do mercado" (SOUZA; CRUZ, 2003). Roberto Setúbal, presidente do Itaú, também mencionou o discurso de Meirelles como fator de "otimismo" no mercado, destacando esse compromisso com o controle da inflação e a afinidade desse discurso com as promessas feitas na "Carta ao povo brasileiro" (SOUZA; CRUZ, 2003). Bernard Mencier, presidente do BNP Paribas, declarou que estava confiante no retorno dos investimentos estrangeiros diante da "situação política" brasileira e das declarações de Palocci e Meirelles nos seus discursos de posse (SOUZA; CRUZ, 2003). Já Gustavo Marin, presidente do Citibank, elogiou a "coerência" do discurso de Meirelles, mas declarou: "Vamos ver os fatos. O discurso prepara o terreno, assim como o jogador prepara uma boa jogada. Ainda precisa vir o centroavante e fazer o gol". (SOUZA; CRUZ, 2003).

$\mathrm{O}$ discurso de Meirelles foi bem recebido entre os banqueiros. A entrada do PT no poder, com o Banco Central sob o comando de Henrique Meirelles e com as políticas econômicas prometidas, teve uma recepção positiva por parte dos banqueiros, fator esse muito relevante para a manutenção da legitimidade da autoridade monetária dos moldes neoliberais.

Mas essa legitimidade foi mantida durante o governo Lula? Não foi possível identificar muitas declarações na imprensa de elogios diretos à Henrique Meirelles. O identificado foi o posicionamento favorável à política de juros implementada no início do governo Lula. Segundo Gabriel Jorge Ferreira, presidente da FEBRABAN: 
“O BC tem atuado neste governo, assim como no governo anterior, com autonomia, tanto que o Copom aumentou os juros básicos da economia neste ano. Essa é a maior demonstração de autonomia do Banco Central [...]." (BARROS, 2003).

Outro posicionamento favorável à essa política de juros foi a de Alexandre Schwartsman, então economista-chefe do Unibanco, que considerou a decisão do COPOM em aumenta-los como "parte do processo de construção da reputação de Henrique Meirelles como presidente da instituição" (RANGEL, 2003).

Para além dessas declarações, o evento que mostrou a legitimidade que a direção do Banco Central possuía diante dos banqueiros foi a transformação do status do cargo de presidente do Banco Central em 17/08/2004, que passou a ter prerrogativas jurídicas semelhantes às dos Ministros do executivo. A conjuntura política desse período estava marcada por acusações contra Henrique Meirelles que iam desde problemas com a Justiça eleitoral até transações financeiras com pessoas acusadas na CPI do Banestado (ENTENDA..., 2004). Essas acusações repercutiram nos relatórios feitos pelos bancos internacionais. Segundo a reportagem do "Valor Econômico", o HSBC, o CSFB e o Lehman Brothers inseriram dentro de seus relatórios comentários acerca dos casos de denúncia (MEIRELLES..., 2004). A reportagem informa ainda que os analistas ouvidos se sentiam "tranquilizados" diante das ações do governo para manter Henrique Meirelles no cargo. Essa transformação jurídica foi uma ação política nesse sentido. Com ela, Meirelles passa a ter direito a foro privilegiado no caso de denúncias. Não foram encontradas declarações dos principais banqueiros brasileiros sobre o assunto, mas é possível perceber que as pessoas vinculadas ao sistema financeiro emitiram opiniões favoráveis a essa mudança.

Segundo o diretor do Banco Brascan, a concentração no Supremo Tribunal Federal das acusações contra Meirelles (o que 
ocorreu com a alteração de status do presidente do BC) facilita a defesa do presidente do Banco Central. Para Alexandre Lintz, estrategista do Banco BNP Paribas, tal modificação traz mais "segurança institucional":

Com a blindagem jurídica, o presidente do BC terá mais tranqüilidade para examinar o ambiente econômico, principalmente no momento em que o país precisa de um ajuste fino, ou seja, crescer sem gerar inflação (RIPARDO, 2004).

Mas também houve posições contrárias. $\mathrm{O}$ economista-chefe do banco Fibra, Guilhermo de Nobrega, declarou:

É verdade que o cargo é muito exposto. Mas equipará-lo a ministro talvez não seja o melhor formato para se dar o foro privilegiado. Afinal, o BC é uma autarquia independente. É desconfortável e estranho saber que o presidente do BC passa a ser visto como um ministro, um funcionário do governo (RIPARDO, 2004).

Mesmo na posição não favorável à medida, nota-se que a preocupação era em como conceder maior autonomia e evitar os ataques que Meirelles estava sofrendo na época. Assim, o problema não estava na finalidade do ato (proteger o presidente do Banco Central), mas nos meios utilizados (que, inclusive, poderiam indicar uma menor autonomia dele).

$\mathrm{O}$ fato de pronunciamentos dos principais banqueiros do Brasil não terem sido encontrados pela pesquisa pode ser explicado pela situação constrangedora que poderia representar a defesa de um agente do governo que estava sendo acusado juridicamente.

Mas os pronunciamentos mencionados anteriormente de agentes vinculados aos bancos revelam que não era do interesse dos bancos a saída de Meirelles do cargo. Assim, é possível inferir que a autoridade monetária presente no governo Lula foi capaz de manter a legitimidade já existente no governo anterior. Todavia, é preciso notar que essa legitimidade, que permitiu a concentração de poder nesse órgão (NOVELLI, 1998), foi definida por opção política. Não houve 
uma reestruturação institucional na qual este órgão passou legalmente a deter atribuições sem a interferência de outros órgãos. Diante disso, as seguintes questões se colocam: tal situação era a mais desejável pelos banqueiros? Ou existia entre eles o desejo de se institucionalizar, juridicamente, o funcionamento autônomo do Banco Central?

\section{O Problema da Institucionalização da Autonomia do Banco \\ Central: o Artigo 192}

Para analisar o problema da autonomia jurídica do Banco Central foi selecionado um acontecimento político específico: o processo de mudança do artigo 192 da Constituição de 1988 ocorrido no ano de 2003.

Segundo a Constituição Federal de 1988, o sistema financeiro brasileiro seria regido de maneira abrangente pelo artigo 192 da Constituição e por uma lei complementar que seria desenvolvida pelo legislativo. Originalmente, esse artigo da Constituição enumerava alguns princípios básicos de ordenamento do sistema financeiro nacional (inclusive colocando a restrição das taxas de juros reais ao máximo de $12 \%$ ao ano, norma que nunca foi respeitado na prática), mas delegava à lei complementar a regulamentação desses princípios, inclusive a regulamentação do funcionamento e das atribuições do Banco Central.

Como relata Ianoni (2010), durante três legislaturas (1991-2003) foi formada a Comissão Especial do Sistema Financeiro. Essa Comissão seria a responsável por desenvolver a legislação complementar para regular o artigo 192. No entanto, essa comissão nunca formulou uma legislação complementar a respeito do assunto. $\mathrm{O}$ que ocorreu foi a aprovação de uma Emenda Constitucional que torna o artigo mais "enxuto" e que passa para o plural a ideia de regulação do artigo por 
"leis complementares", tornando possível uma regulação fatiada do sistema financeiro.

A leitura que Moscogliato (2010) faz desse processo é muito interessante. Segundo ele, o Congresso preferiu um processo legislativo mais lento e custoso (alteração da Constituição) ao invés de decidir sobre o ordenamento jurídico que regula o assunto (aprovação de lei ordinária). Esse é um fato que demonstra o alto nível de impasse que representava esse tema. É interessante notar que, a despeito de Ianoni ter identificado alguns projetos de lei que dizem respeito ao sistema financeiro brasileiro, o artigo 192 continua com vários pontos sem regulamentação.

Como coloca Miranda (2003), esse tema foi intensamente discutido no âmbito da FEBRABAN no período anterior ao que está sendo estudado. Existia dentro da Diretoria Executiva da entidade uma comissão responsável pela discussão do tema (MIRANDA, 2003, p. 211) e os banqueiros sempre estiveram presentes na Comissão Parlamentar responsável pelo desenvolvimento da lei complementar (MIRANDA, 2003, p. 212).

Existia nessa lei constitucional uma limitação legal da taxa de juros reais a $12 \%$, taxa essa muito discrepante com a prática de juros no Brasil. Segundo Miranda, o posicionamento dos banqueiros era favorável à alteração da lei constitucional, pois, além da retirada dessa limitação à taxa de juros, cada segmento do sistema financeiro seria regulado individualmente segundo o projeto de reforma Constitucional (MIRANDA, 2003, p. 212-213).

Mas com relação ao Banco Central, essa alteração constitucional não resolvia o problema de consolidar institucionalmente o controle da política monetária nessa instituição. Logo após a chegada do PT ao governo, em março de 2003, o presidente da FEBRABAN, Gabriel Jorge Ferreira, declara-se favorável à política do governo Lula em relação ao Banco Central. Na ocasião, Ferreira afirmou que o Banco 
Central estava efetivamente atuando como autônomo e que a reforma institucional da instituição dependia de condições políticas. Assim se manifestou o dirigente: "Acho que o governo tem uma agenda política e ele, melhor do que ninguém, sabe avaliar a conveniência ou não de sobrepor temas polêmicos como esse e mais as reformas tributária, previdenciária e política no Legislativo." (BARROS, 2003).

Para o presidente da FEBRABAN, o que deveria ocorrer era a aprovação da reforma da lei 192, fragmentando a regulação do sistema financeiro, permitindo que o governo decidisse a melhor circunstância política para reformar o Banco Central. Mas segundo o banqueiro, "o ideal seria que o governo encaminhasse logo o projeto de lei de autonomia do BC para o Congresso" (BARROS, 2003). Quando houve a aprovação da alteração do Artigo 192 no Senado, a FEBRABAN lançou nota elogiando a decisão, mencionando a importância desta para o desenvolvimento do sistema financeiro brasileiro, falando que foi um "passo fundamental na evolução institucional da nação brasileira" (FEBRABAN..., 2003). Existia a "vontade" política entre os banqueiros de uma regulação institucional da autonomia do Banco Central, mas essa regulação não chegou a se realizar.

Ao sair da FEBRABAN e assumir a presidência da Confederação Nacional das Instituições Financeiras (CNF), em 2004, Gabriel Jorge Ferreira fala que sua maior "frustração" quando estava na presidência da instituição anterior foi o "engessamento" do artigo 192 (FEBRABAN..., 2004). Segundo Ferreira, o Banco Central já agia como autônomo, mas a institucionalização dessa autonomia “deve afastar qualquer pressão política, por isso será saudável [...] Não há pressão, mas sempre fica a incerteza de que algum ministro pode mudar sua forma de pensamento.» (FEBRABAN..., 2004). Não foram identificados outros pronunciamentos de banqueiros acerca da necessidade da institucionalização da autonomia do Banco Central. Em 2006 (ano em que Lula se reelegeu) houve o elogio de Roberto 
Luis Troster, economista-chefe da FEBRABAN, à reformulação do artigo 192, mas não houve nenhuma menção à necessidade de se institucionalizar a autonomia do Banco Central (DELGADO; ZANINI, 2006).

Esse não-pronunciamento dos banqueiros pode significar ou que os banqueiros ficaram satisfeitos com o tipo de autonomia que foi aplicada no Brasil, ou que eles não encontraram condições políticas para reivindicar a institucionalização da autonomia do Banco Central. Mas, independente disso, essa institucionalização foi efetivamente uma reivindicação, e essa reivindicação foi frustrada.

\section{Conclusẽo}

Existia um grande dilema no início do governo Lula, que seria a aceitação de seu governo por parte da classe dominante. Os abalos econômicos ocorridos em 2002 na conjuntura eleitoral e a cobranças de vários setores por meio da mídia por "respeito a contratos" indicavam que a legitimidade do governo do PT precisava ser construída diante da classe dominante.

Algumas atitudes por parte dos integrantes do Partido dos Trabalhadores foram tomadas no sentido de obter essa aceitação, essa legitimidade. A "Carta ao Povo Brasileiro" foi uma dessas medidas. A escolha cuidadosa da equipe econômica do Banco Central foi outra medida importante.

A política governamental aplicada pelo PT manteve o foco monetarista nos objetivos do Banco Central, não alterando as relações entre os atores do "jogo de barganha bancário". É possível concluir que essa política monetária, assim como a estrutura institucional que comanda essa política, foi considerada aceitável pelos banqueiros. Os elogios à política aplicada por Henrique Meirelles são evidências nesse sentido. Mas nesse jogo os banqueiros não tiveram todas as suas 
reivindicações atendidas. Embora um grande empecilho legal tenha sido resolvido no período (reformulação do artigo 192 da Constituição), a reivindicação de institucionalizar a autonomia do Banco Central não foi atendida.

A análise da luta política pela construção da autonomia do Banco Central mostra a atuação de dois conjuntos de atores importantes: banqueiros e governo. Ocorreu a entrada de um novo governo, buscando ser aceito dentro do jogo. Não se tratou de uma pura obediência do governo diante da vontade dos banqueiros; e nem de uma força inevitável que constrangia completamente os agentes públicos. Foi um governo que entrou em um jogo cujos termos já estavam estabelecidos. Esses termos eram favoráveis aos bancos, e, por decisão política, esses termos não foram discutidos.

\section{REFERÊNCIAS}

BARROS, Guilherme. BC já age como autônomo, diz Febraban. Folha de São Paulo, São Paulo, 28 mar. 2003. p. 3. Disponível em: <http://www1.folha.uol.com.br/fsp/ brasil/ fc2803200315.htm>. Acesso em: 16 jun. 2016.

BLINDER, Alan S. Bancos centrais: teoria e prática. São Paulo: Ed. 34. 1999.

CALOMIRIS, Charles; HABER, Stephen. Fragile by design: the political origins of banking crises \& scarce credit. Princeton: Princeton University Press. 2014.

CAVALIERI, Marco Antonio Ribas; PERISSINOTTO, Rento Monseff; DANTAS, Eric Gil. Mainstream econômico e poder: uma análise do perfil dos diretores do Banco Central do Brasil nos governos do PSDB e do PT. In: ENCONTRO NACIONAL DA ANPOCS, 39., 2015, Caxambu. Anais...Caxambu, 2015.

COMBATE à inflação foi ponto principal, diz Cristiano Buarque. Valor Econômico, São Paulo, 7 jan 2003. Disponível em: <http://www.valor.com.br/arquivo/335531/ combate-inflacao-foi-ponto-principal-diz-cristiano-buarque>. Acesso em: 16 jun. 2016.

DELGADO, Malu; ZANINI, Fábio. Lula acena a empresários e foge do estigma de "pai dos bancos". Folha de São Paulo, São Paulo, 26 jul. 2006. Disponível em: http:// www1.folha.uol.com.br/fsp/brasil/fc2607200613.htm. Acesso em: 16 jun. 2016. 
DIRCEU almoça com Itamar e descarta permanência de Fraga no BC. Folha de São Paulo, São Paulo, 20 nov. 2002. Disponível em: <http://www1.folha.uol.com.br/ folha/brasil/ ult96u42632.shtml>. Acesso em: 16 jun. 2016.

ENTENDA o que dizem as acusações sobre Meirelles, Casseb e Candiota. Folha de São Paulo, São Paulo, 5 abr. 2004. Disponível em: <http://www1.folha.uol.com.br/ folha/ brasil/ult96u62978.shtml>. Acesso em: 16 jun. 2016.

FEBRABAN defende votação da autonomia do BC pelo Congresso neste ano. Valor Econômico, São Paulo, 20 jan. 2004. Disponível em: <http://www.valor.com.br/ arquivo/398759/febraban-defende-votacao-da-autonomia-do-bc-pelo-congressoneste-ano. Acesso em: 16 jun. 2016.

FEBRABAN divulga nota de apoio à votação da PEC. Folha de São Paulo, São Paulo, 3 abr. 2003. Disponível em: <http://www1.folha.uol.com.br/fsp/brasil/fc0304200303. htm>. Acesso em: 16 jun. 2016.

FLUXO negativo faz dólar aumentar 0,4\%. Folha de São Paulo, São Paulo, 13 dez. 2002. Disponível em: http://www1.folha.uol.com.br/fsp/dinheiro/fi1312200228.htm. Acesso em: 16 jun. 2016.

FRAGA, Erica; AITH, Marcio. Desconfiado, mercado espera por técnicos. Folha de São Paulo, São Paulo, 13 dez. 2002. Disponível em: <http://www1.folha.uol.com.br/ fsp/ brasil/fc1312200208.htm>. Acesso em: 16 jun. 2016.

FREIRE, Felipe. Fraga diz que sai do BC, mas diretores aceitariam ficar. Folha de São Paulo, São Paulo, 12 dez. 2002. Disponível em: <http://www1.folha.uol.com.br/ folha/brasil/ ult96u43449.shtml>. Acesso em: 16 jun. 2016.

IANONI, Marcus. Ciência política e sistema financeiro no Brasil: o artigo 192 da Constituição Federal. Política e Sociedade, Florianópolis, v. 9, n. 17, 2010.

LOUREIRO, Maria Rita; SANTOS, Fábio Pereira dos; GOMIDE, Alexandre de Ávila Democracias, arenas decisórias e política econômica do governo Lula. Revista Brasileira de Ciências Sociais, São Paulo, v. 26, n. 76, 2011.

MEIRELLES chega aos relatórios de bancos. Valor Econômico, São Paulo, 10 out. 2004. Disponível em: <http://www.valor.com.br/arquivo/426287/meirelles-chegaaos-relatorios-de-bancos>. Acesso em: 16 jun. 2016.

MEIRELLES reafirma que atual diretoria do BC permanece por algum tempo. Valor Econômico, São Paulo, 27 dez. 2002a. Disponível em: <http://www.valor.com. br/arquivo/334119/meirelles-reafirma-que-atual-diretoria-do-bc-permanece-poralgum-tempo>. Acesso em: 16 jun. 2016.

MEIRELLES tem a confiança do mercado financeiro, diz Febraban. Valor Econômico, São Paulo, 12 dez. 2002b. Disponível em: <http://www.valor.com.br/ 
arquivo/331595/meirelles-tem-confianca-do-mercado-financeiro-diz-febraban>. Acesso em: 16 jun. 2016.

MEIRELLES, Henrique. Discurso de posse. 2003. Disponível em: <http://www1.uol. com.br/fernandorodrigues/030106/discurso_de_posse-banco_central.doc $>$. Acesso em: 16 jun. 2016.

MENDONÇA, Helder Ferreira. A teoria da independência do Banco Central: uma interpretação crítica. Estudos Econômicos, São Paulo, v. 30, n. 1, p. 101-127, 2000.

MIGUEL Jorge espera que Meirelles forme equipe coesa no BC. Valor Econômico, São Paulo, 13 dez. 2002. Disponível em: <http://www.valor.com.br/arquivo/331837/ miguel-jorge-espera-que-meirelles-forme-equipe-coesa-no-bc $>$. Acesso em: 16 jun. 2016.

MIRANDA, Elflay. Globalização financeira e associações de bancos no Brasil: o caso da Febraban. Sociedade e Cultura, Goiânia, v. 6, n. 2, 2003.

MOSCOGLIATO, Marcelo. A regulamentação do artigo 192 da Constituição Federal: inclusão bancária e responsabilidade socioambiental no sistema financeiro - alguns aspectos. 2010. Disponível em: <http://www.sinal.org.br/artigo192/Seminario_ Sinal_e_Ipea/Artigo\%20Dr\%20Marcelo\%20Moscogliato\%20MPF.pdf $>$. Acesso em: 16 jun. 2016

NOVELLI, José Marcos Nayme. O campo dos economistas e o debate sobre a independência do Banco Central do Brasil pós-64. In: INTERNATIONAL CONGRESS OF THE LATIN AMERICAN STUDIES ASSOCIATION, 21., 1998, Chicago. Anais...Chicago, 1998.

PERFIL político de Meirelles preocupa Wall Street. Valor Econômico, São Paulo, 13 dez. 2002. Disponível em: <http://www.valor.com.br/arquivo/331679/perfil-politicode-meirelles-preocupa-wall-street>. Acesso em: 16 jun. 2016.

PINTO, Celso. PT mostra sinais moderados para os bancos. Folha de São Paulo, São Paulo, 26 set. 2002. Disponível em: <http://www1.folha.uol.com.br/folha/ dinheiro/ ult91u56147.shtml>. Acesso em: 16 jun. 2016.

PRESIDENTE da Febraban avalia Hermann como "empresário competente". Valor Econômico, São Paulo, 13 dez. 2002. Disponível em: <http://www.valor.com. br/arquivo/331881/presidente-da-febraban-avalia-hermann-como-empresariocompetente>. Acesso em: 16 jun. 2016.

RANGEL, Juliana. Alta de juros buscou dar credibilidade a Meirelles, dizem economistas. Valor Econômico, São Paulo, 22 jan. 2003. Disponível em: <http:// www.valor.com.br/arquivo/338447/alta-de-juros-buscou-dar-credibilidademeirelles-dizem-economistas>. Acesso em: 16 jun. 2016. 
RIBEIRO, Silvia. Indicação de Meirelles, do PSDB, não é contraditória, diz Febraban. Valor Econômico, São Paulo, 12 dez. 2002. Disponível em: <http://www. valor.com.br/ arquivo/331629/indicacao-de-meirelles-do-psdb-nao-e-contraditoriadiz-febraban>. Acesso em: 16 jun. 2016.

RIPARDO, Sérgio. Lula "blinda" e fortalece Meirelles ao torná-lo ministro, dizem analistas. Folha de São Paulo, São Paulo, 17 ago. 2004. Disponível em: <http:// www1.folha.uol.com.br/folha/dinheiro/ult91u87869.shtml>. Acesso em: 16 jun. 2016.

RIPARDO, Sérgio. PT atrasa indicação para BC, frustra mercado e derruba Bovespa. Folha de São Paulo, São Paulo, 5 dez. 2002. Disponível em: <http://www1. folha.uol.com.br/ folha/dinheiro/ult91u60237.shtml>. Acesso em: 16 jun. 2016.

SOLA, Lourdes; GARMAN, Christopher; MARQUES, Moises. Central banking, democratic governance and political authority: the case of Brazil in a comparative perspective. Revista de Economia Política, São Paulo, v. 18, n. 2, 1998.

SOUZA, Leonardo; CRUZ, Ney. Banqueiros elogiam declarações do novo presidente do Banco Central. Folha de São Paulo, São Paulo, 8 jan. 2003. Disponível em: <http://www1.folha.uol.com.br/fsp/dinheiro/fi0801200304.htm>. Acesso em: 16 jun. 2016. 